\title{
EL CASO GLADIO: \\ Una red militar clandestina en la Italia de la Guerra Fría
}

\author{
Juan Avilés ${ }^{1}$ \\ Instituto Universitario "General Gutiérrez Mellado"/UNED
}

\section{Resumen:}

Durante la Guerra Fría existió una red clandestina vinculada a la OTAN, denominada StayBehind, cuya misión habría sido actuar tras las líneas enemigas en caso de invasión soviética. Puesto que la invasión nunca se produjo, esta red nunca actuó y su existencia habría permanecido oculta si el presidente del Gobierno italiano Giulio Andreotti, no la hubiera revelado en 1990. La rama italiana de Stay-Behind era conocida como Gladio y, aunque las investigaciones judiciales y parlamentarias no han hallado prueba alguna de su implicación en actividades delictivas, se ha difundido una teoría de la conspiración que la implica en el terrorismo de los "años de plomo". Este artículo refuta dicha teoría sobre la base de la amplia documentación sobre el tema hoy accesible a los investigadores, y plantea también cuáles son los puntos todavía no esclarecidos en la historia de Gladio.

Palabras Clave: Gladio, Stay-Behind, OTAN, Guerra Fría, servicios secretos, teorías de la conspiración.

Title in English: Gladio: A clandestine military network in Cold War Italy

\section{Resumen:}

During the Cold War, Stay-Behind was a clandestine network connected to NATO whose mission would have been to act behind enemy lines in the event of a Soviet invasion. Since the invasion never took place, this network never acted and its existence would have remained hidden if the president of the Italian government, Giulio Andreotti, had not disclosed it in 1990. The Italian branch of Stay-Behind was known as Gladio and, although judicial and parliamentary inquiries have not found any evidence of its involvement in criminal activities, a conspiracy theory that maintains its responsabilty in the terrorism of the "lead years" has been spread. This article refutes that theory on the basis of the extensive documentation on the subject now available to researchers and addresses the points that have not yet been clarified in Gladio's story.

Key Words: Gladio, Stay-Behind, NATO, Cold War, secret services, conspiracy theories.

Copyright (C) UNISCI, 2019.

Las opiniones expresadas en estos artículos son propias de sus autores, y no reflejan necesariamente la opinión de UNISCI. The views expressed in these articles are those of the authors, and do not necessarily reflect the views of UNISCI.

\footnotetext{
${ }^{1}$ Juan Avilés es Catedrático de Hisoria Contemporánea de la UNED y Profesor del Instituto Universitario

"General Gutiérrez Mellado".

E-mail: <javiles@geo.uned.es >

DOI: http://dx.doi.org/10.31439/UNISCI-59
} 


\section{Introducción}

En 1952, en uno de los momentos de mayor tensión de la Guerra Fría, debido a la guerra de Corea, varios Estados miembros de la OTAN acordaron la creación de Stay-Behind, una red clandestina, inspirada en la acción de la Resistencia durante la Segunda Guerra Mundial, que habría de actuar tras las líneas enemigas en caso de invasión soviética. Puesto que la temida invasión nunca se produjo, Stay-Behind nunca entró en acción y su existencia habría quedado olvidada, oculta entre la documentación no desclasificada de los servicios de inteligencia aliados, si el presidente del gobierno italiano, el democristiano Giulio Andreotti, no la hubiera dado a conocer en octubre de 1990.

Italia no se incorporó a Stay- Behind hasta 1959, pero ya en 1956 había puesto en marcha una red semejante mediante un acuerdo bilateral del SIFAR, su servicio de inteligencia militar, con la CIA. Ese acuerdo dio origen a la llamada operación Gladio, a la que se incorporaron fuerzas procedentes de una estructura militar clandestina creada ya en la inmediata posguerra mundial en previsión de un ataque procedente del Este. La peculiaridad de Italia era que la existencia de un poderoso Partido Comunista hacía prever que una eventual invasión soviética tuviera un significativo apoyo local, con lo cual la distinción entre la defensa frente a la amenaza exterior y la actuación anticomunista en el interior podía desdibujarse, si no en el plano teórico, sí en el ánimo de algunos miembros de la red Gladio. Por otra parte, Italia había sufrido a partir de 1969 una sucesión de gravísimos atentados cometidos por militantes neofascistas, que se sospechaba habían contado con la complicidad de agentes del Estado. Así es que cuando Andreotti dio a conocer la existencia de una estructura militar secreta vinculada a la OTAN, surgieron voces que la acusaron de haber promovido el terrorismo neofascista en el marco de una estrategia de la tensión encaminada a sembrar el miedo en la población y frenar así el avance del Partido Comunista Italiano. El secretario general de este partido, Achille Occhetto, relacionó a Gladio con una vasta conspiración contra la democracia, responsable tanto de las matanzas como de las tramas golpistas. ${ }^{2}$

Nunca han aparecido pruebas de ello, así es que la hipótesis de la implicación de Gladio, y por tanto de la OTAN, en actividades terroristas no pasa de ser una teoría de la conspiración infundada, pero una consulta realizada el 17 de mayo de 2019 en Wikipedia, un medio al que es muy común acudir para encontrar la primera referencia respecto a un tema, muestra su amplia difusión. La versión inglesa menciona la tesis del autor suizo Daniele Ganser que vincula a Stay-Behind y especialmente a la Gladio italiana con el terrorismo ultraderechista, pero menciona también las reseñas que reprochan a su libro la falta de apoyo documental de sus tesis conspirativas $^{3}$ y concluye que la amplitud de las actividades de Gladio durante la Guerra Fría y su supuesto papel en los atentados terroristas de los años de plomo en Italia son objeto de debate. Menciona muy de pasada el único estudio general sobre las redes Stay-Behind basado en una investigación rigurosa que se ha publicado hasta ahora, el dossier editado por Leopoldo Nuti y Olav Riste, ${ }^{4}$ pero no cita ninguna de las publicaciones italianas más relevantes, ni siquiera el libro fundamental en que Giacomo Pacini ha analizado la historia de Gladio y de las estructuras clandestinas que la precedieron en Italia. ${ }^{5}$ La versión española menciona en su introducción la tesis de Ganser, pero advierte que es totalmente rechazada por la gran mayoría de los

\footnotetext{
${ }^{2}$ L'Unità, 29/10/1990.

${ }^{3}$ Hansen, Peer Henrik: "Review of NATO's Secret Armies," Journal of Intelligence History.vol.5 n ${ }^{\circ} 1(2005)$ pp.110-113. Hansen, P. H.: A review of "Falling Flat on the Stay-Behinds" International Journal of Intelligence and Counterintelligence, vol. 19, $\mathrm{n}^{\circ} 1$ (2006). Davies, Philip: "Review of NATO's Secret Armies," The Journal of Strategic Studies (2005). Riste, Olav: "Review of NATO’s Secret Armies," Intelligence and National Security (2005)

${ }^{4}$ Nuti, Leopoldo y Riste, Olav, (eds.): "Preparing for a Soviet Occupation: the Strategy of Stay-Behind", Journal of Strategic Studies, vol.30, nº 6 (2007).

${ }^{5}$ Pacini, Giacomo (2014): Le altre Gladio: la lotta segreta anticomunista in Italia, 1943-1991, Turín, Einaudi.
} 
historiadores. Sin embargo, en la sección titulada "Qué fue Gladio", asume por completo la teoría conspirativa al afirmar que empleó varias estrategias de guerra sucia, tales como la infiltración, y las operaciones de bandera falsa, incluida la matanza terrorista en la estación de Bolonia, en 1980, para destrozar la imagen pública de los comunistas y otros partidos al señalarlos falsamente como los autores de los atentados (una tesis absurda porque en 1980 todo el mundo conocía en Italia la firme posición antiterrorista adoptada por el Partido Comunista Italiano). La introducción más conspirativa se encuentra en la versión italiana, según la cual la operación Gladio fue creada al servicio de la CIA y de la OTAN para actuar más allá de las líneas enemigas en caso de un eventual ataque de las fuerzas del Pacto de Varsovia y también para combatir al comunismo mediante formas de guerra psicológica y operaciones de falsa bandera. La sección sobre "Gladio, la estrategia de la tensión y las injerencias extranjeras en Italia" es sin embargo algo más prudente, pues se limita a afirmar que, aunque nada se haya probado, existen muchas hipótesis sobre las relaciones de Gladio con la subversión, los atentados terroristas o los intentos de golpe de Estado que habían tenido lugar en Italia. Sorprendentemente, su bibliografía menciona el libro de Ganser, pero no el de Pacini.

En resumen, si un ciudadano interesado recurre a Wikipedia no encontrará una información precisa sobre la red Stay-Behind ni sobre Gladio, pero sí alusiones a teorías de la conspiración no fundadas y quizá concluya que para informarse a fondo deba leer a Ganser. Sin embargo, este autor suizo es un ejemplo clásico del teórico de la conspiración que se apoya en algunos datos sueltos para componer una teoría basada en sus prejuicios ideológicos y que pueda darle notoriedad. De hecho, su libro puede consultarse en el sitio de Internet de la red Voltaire, ${ }^{6}$ cuyo presidente es Thierry Meissan, autor de un best-seller, traducido a más de veinte lenguas, cuya tesis es que los atentados del 11 de septiembre de 2001 fueron el resultado de una conspiración del complejo militar-industrial estadounidense encaminada a manipular a la opinión pública. La falta de rigor de Ganser en su tratamiento del caso italiano se manifiesta, por ejemplo, en que presenta el informe final de la minoría del Partido Democrático de Izquierda en la Comisión parlamentaria de investigación sobre el terrorismo como un informe de la propia Comisión, cuando lo cierto es que esta nunca llegó a consensuar un informe final. También confunde a la sección del servicio secreto militar que gestionaba Gladio desde Roma con su centro de adiestramiento en Cerdeña, aunque ello implique leer las siglas SAD (Studi ed Addestramento, es decir Estudios y Adiestramiento) como Sección de Adiestramiento de Gastadores (la base sarda se camuflaba bajo la denominación de Centro de Adiestramiento de Gastadores). Dada esta falta de precisión y las escasas fuentes documentales que cita, es sorprendente que se haya podido dar crédito a su tesis de que Gladio, en alianza con el terrorismo de derechas y con el apoyo de la Democracia Cristiana, estuvo implicado en una guerra subterránea anticomunista dirigida por Estados Unidos. ${ }^{7}$

Los archivos de las redes Stay-Behind siguen cerrados a los investigadores en la mayoría de los países, pero no en Noruega, donde se han abierto para el período anterior a 1970, ni en Italia, donde las investigaciones judiciales y parlamentarias sacaron a la luz mucha documentación hoy accesible a los investigadores. Este artículo emplea fuentes primarias italianas, incluidos informes parlamentarios, documentos judiciales y documentos directos de Gladio hoy desclasificados, para responder a tres cuestiones: qué fue Stay-Behind, qué fue en particular Gladio y qué indicios hay de su supuesta relación con el terrorismo italiano de los años de plomo. La documentación ha sido consultada en el Archivo Histórico del Senado de la República, el Archivo Central del Estado, el Archivo Flamigni y el Centro de Documentación

\footnotetext{
${ }^{6}$ Red Voltaire, en

https://www.voltairenet.org/spip.php?page=recherche\&lang=es\&recherche=ganser $\& \mathrm{x}=8 \& \mathrm{y}=8$,

${ }^{7}$ Ganser, Daniele (2005): Gli eserciti segreti della Nato: operazione Gladio e terrorismo in Europa occidentale, Roma, Fazi, pp. 22, 83 y 87.
} 
Cultura y Legalidad Democrática, lugares en los que he encontrado un caluroso apoyo a mi investigación.

\section{Los orígenes de Stay-Behind}

Los orígenes de esta red se remontan al 7 de agosto de 1951, fecha en que el general Eisenhower, Supremo Comandante Aliado en Europa, propuso al Grupo Permanente del Comité Militar de la OTAN, integrado por Estados Unidos, Gran Bretaña y Francia, la constitución de un Comité Clandestino de Planificación (CPC). La propuesta fue aprobada por el Grupo Permanente el 4 de septiembre de 1952 y al CPC se adhirieron como miembros asociados Dinamarca, Noruega, Holanda, Bélgica, Luxemburgo, Grecia y Turquía. Varios servicios de inteligencia aliados propusieron al SIFAR, el servicio de inteligencia militar italiano, que se incorporara al CPC, pero el Jefe del Estado Mayor se mostró reacio a que Italia se integrara en una posición que no fuera por completo paritaria respecto a los tres miembros del Grupo Permanente. Así es que Italia no se incorporó al CPC como miembro asociado hasta 1959, tres años después de la creación de Gladio. El CPC, que en 1959 pasó a denominarse Comité de Planificación y Coordinación, fue el máximo órgano coordinador de las redes StayBehind. $^{8}$

Los orígenes de la red europea Stay-Behind han sido estudiados por un grupo de investigadores encabezados por el italiano Leopoldo Nuti y el noruego Olav Riste. El impulso para la creación de la red vino de las experiencias de los países europeos que sufrieron la ocupación nazi y del temor de que la historia volviera a repetirse en forma de una invasión soviética, dos factores que tenían una gran fuerza no sólo intelectual sino emocional. Entre los fundadores de Stay-Behind en los distintos países hubo una fuerte presencia de civiles y militares que habían participado en la Resistencia y habían mantenido contactos con los servicios de inteligencia extranjeros que la habían apoyado, el Office of Strategic Services (OSS) estadounidense y el Special Operations Executive (SOE) británico. En Estados Unidos el OSS fue disuelto tras el final de la guerra mundial y no fue hasta 1948 cuando, coincidiendo con el inicio de la Guerra Fría, la CIA, comenzó a planear operaciones encubiertas. Los británicos, en cambio, comenzaron a pensar en el papel que iban a jugar las operaciones especiales después de la guerra antes de que esta acabara. Las actividades del SOE fueron asumidas por el M16, que estableció contactos con las embrionarias redes Stay-Behind de los Países Bajos, Bélgica y Noruega. En 1949 se estableció un comité tripartito en los Países Bajos con participación de la CIA y el M16 y al año siguiente otro similar en Bélgica. Francia, oficialmente reconocida como una de las potencias vencedoras en la guerra, mostró muy pronto su interés en que los miembros de la OTAN coordinaran sus operaciones clandestinas. Todo ello condujo a la citada decisión de dar inicio a la coordinación de las redes que habrían de actuar tras las líneas enemigas en el caso de una invasión soviética. La cuestión más difícil, concluyen Nuti y Riste, es la de si en algún país la red Stay-Behind asumió también la función de combatir a los "enemigos internos", tal como los críticos de Gladio sostuvieron que había ocurrido en Italia."

\section{La Brigada Ossopo}

En el caso italiano los orígenes de Gladio se remontan también a experiencias de la Segunda Guerra mundial y más específicamente a lo ocurrido en el Friuli-Venecia Julia, la región fronteriza con Yugoslavia, en la que las líneas de demarcación entre las poblaciones eslavas e italianas no eran nítidas, las respectivas aspiraciones nacionales de ambos Estados habían

\footnotetext{
8 “Comitato Parlamentare per i Servizi d'Informazione e Sicurezza e per il segreto di Stato (Copasis): Relazione", 4-3-1992., pp. 15-16.

${ }^{9}$ Nuti, Leopoldo y Riste, Olav.: "Introduction: Strategy of Stay-Behind”, Journal of Strategic Studies, vol.30, nº 6 (2007), pp.:929-935.
} 
chocado en el pasado, el intento de italianización forzosa impuesto por el régimen fascista envenenó aún más el ambiente y las atrocidades contra la población civil eslava durante la Segunda Guerra Mundial, tanto en territorio italiano como en territorio yugoslavo ocupado, incrementaron el odio. ${ }^{10}$ Luego, la caída de Mussolini en septiembre de 1943 modificó radicalmente el panorama. El nuevo gobierno monárquico, que controlaba el sur, pasó a combatir a la Alemania nazi junto a los aliados, mientras que, en el Norte, que permaneció bajo control nazi-fascista, surgieron formaciones partisanas. En el Friuli-Venecia Julia coexistieron, en un principio sin choques, dos organizaciones de la Resistencia: las Brigadas Garibaldi, de orientación comunista, y la Brigada Ossopo, fundada por militantes católicos y liberales y oficiales del Ejército y respaldada por el clero. Las relaciones entre ambas formaciones se tensaron cuando en octubre de 1944 el líder comunista Palmiro Togliatti, presionado por los comunistas yugoslavos, ordenó las Brigadas Garibaldi de la región que se pusieran bajo las órdenes del IX Cuerpo esloveno, cuya ocupación de aquel territorio italiano permitiría, según Togliatti, una depuración antifascista y una transformación social que resultaban imposibles en las zonas ocupadas por los anglo-americanos. En febrero de 1945 los partisanos comunistas de la región atacaron a sus rivales en el más grave choque interno en el seno de la Resistencia italiana. Veinte combatientes de la Ossopo capturados a traición en Porzûs fueron fusilados, un crimen que ha generado una intensa polémica política e historiográfica. ${ }^{11}$ A ello se sumó la ejecución de miles de italianos por los partisanos yugoslavos a partir del otoño de 1943. El caso de quienes fueron arrojados, a veces todavía vivos, a las cavidades kársticas conocidas localmente como foibe fue el más emblemático, aunque no el más común. ${ }^{12} \mathrm{Al}$ final, Stalin cedió respecto a Trieste ante las potencias occidentales e impuso a los yugoslavos la retirada de la ciudad, que quedó bajo control occidental pero no se incorporó definitivamente a Italia hasta 1954. Todo ello dejó un legado de odio y miedo que perduraría durante décadas en la región y condujo a que la Brigada Ossopo permanecerá secretamente en activo tras el fin de la guerra, dispuesta a actuar contra una eventual invasión llegada de Este, a la que los comunistas locales habrían dado la bienvenida.

La historia de las sucesivas trasmutaciones de la Brigada Ossopo de 1945 a 1956 fue expuesta por quien fuera su jefe, el coronel Luigi Olivieri, en un extenso informe que el juez Felice Casson localizó en 1990. Según su hoja de servicios, el coronel pasó a la reserva el 2 de junio de 1947, cuando iba a cumplir 65 años, pero se le mantuvo en activo para que siguiera al mando de la formación voluntaria clandestina formada a partir de veteranos de la Ossopo que en mayo de 1946 había comenzado a funcionar como 3er Cuerpo de Voluntarios de la Libertad. Este cuerpo clandestino estuvo bajo dependencia directa de la presidencia del Gobierno desde 1948 hasta 1950, año en que pasó a depender del Estado Mayor del Ejército, asumiendo la denominación de Organización O. Se trataba de unidades exclusivamente militares, con uniformes militares y sujetas al código militar, que sólo saldrían a la luz en caso de movilización. Olivieri fue siempre su elemento propulsor y animador. ${ }^{13}$

El informe del propio Olivieri proporciona más información. El 4 de junio de 1945 se desmovilizaron y entregaron las armas 8.700 hombres de la brigada Ossopo-Friuli y 6.971 de las brigadas Garibaldi. Sin embargo, según la versión de Olivieri, las aspiraciones anexionistas yugoslavas, apoyadas por los comunistas locales, se tradujeron en la intimidación de la población italiana, sin que el Mando Aliado interviniera para ponerle fin, lo que condujo a que,

\footnotetext{
${ }^{10}$ Scotti, Giacomo (2005): Dossier foibe. San Cesareo di Lecce, Manni, pp. 15-55.

${ }^{11}$ Aga-Rossi, Elena: "L'eccidio di Porzûs e la sua memoria", en Piffer, Tommaso (ed.) (2012): Porzûs: Violenza e Resistenza sul confine orientale, Bolonia, Il Mulino.

12 Oliva, Gianni (2002): Foibe: le stragi negate degli italiani della Venezia Giulia e dell'Istria, Milano, Mondadori, pp. 76-87.

${ }^{13}$ Stato di servicio militare del col. Olivieri Luigi, Centro di Documentazione Cultura della Legalità Democratica (CLD), Florencia, CS, S2388:
} 
en enero de 1946, miembros de la Ossopo decidieran reorganizarse. Eligieron como jefe a Olivieri, que había sido el Jefe de Estado Mayor de la brigada, e informaron de su decisión al general Cadorna, Jefe de Estado Mayor del Ejército. En dos meses se reclutaron 2.150 hombres y en abril de 1946 el general Cadorna envió a un coronel para que contactara con Olivieri y fijara las tareas de la organización, que serían las de animar la resistencia frente a las pretensiones anexionistas yugoslavas, incrementar el reclutamiento, vigilar la línea fronteriza y actuar frente a eventuales infiltraciones, todo ello manteniendo el máximo secreto, para evitar que se pudiera responsabilizar el Ejército. En septiembre de 1947 el Cuerpo de Voluntarios de la Libertad contaba con 4484 hombres, entre los que se encontraban elementos seguros de todas las tendencias políticas, salvo socialistas y comunistas. Con ocasión de las cruciales elecciones de 1948, en las que la Democracia Cristina triunfó frente a comunistas y socialistas, el CVL desplegó clandestinamente a mil hombres en la frontera y el 26 de abril miembros del mismo apoyaron a una patrulla italiana en un tiroteo con otra yugoslava, lo que llevó a que fuera detectado por el servicio de información del Partido Comunista Italiano. Por ello se fingió la disolución del CVL, que en abril de 1950 se transformó en la Organización O, cuya jefatura se ocultó tras la inocua denominación de Oficina de Monografías del V Mando Militar Territorial. La nueva organización O contaba con 256 oficiales, 496 suboficiales y 5728 soldados, agrupados en 20 batallones. El reclutamiento, que se había iniciado con antiguos miembros de la Ossopo, se había extendido a oficiales y suboficiales en la reserva y a partir de conocimientos personales se había reclutado a la tropa. En septiembre de 1954 el jefe de la supuesta Oficina de Monografías era el coronel Luigi Oliveri, al mando de sus cuatro zonas se hallaban el propio Olivieri, el mayor en la reserva Fausto Manai, el general en la reserva activa Angelo Valtulina y el teniente coronel en la reserva Giovanni Manca. El responsable de la sección de materiales era el capitán en servicio activo Aldo Specogna, que jugaría un polémico papel en la historia de Gladio, y a sus órdenes se hallaba un trabajador civil, Lino Micoli, que muchos años después haría unas declaraciones muy comprometedoras para Specogna. ${ }^{14}$

\section{La Operación Gladio}

Durante años el Ejército italiano había mantenido una organización clandestina en la frontera Nordeste al margen de todo acuerdo internacional, pero en el otoño de 1956 optó por montar una nueva estructura mediante un pacto bilateral con Estados Unidos. El día 4 de noviembre las tropas del Pacto de Varsovia habían invadido Hungría y la tensión internacional subsiguiente quizá no fuera ajena a la decisión de llegar al acuerdo del 28 de noviembre que dio origen a la Operación Gladio. Desde la perspectiva de Washington Italia era un aliado crucial y la preocupación por una posible toma del poder por los comunistas apareció en todos los documentos secretos en que el Consejo Nacional de Seguridad (NSC) fue trazando las líneas de la política estadounidense hacia ella. Todavía en 1961, durante la administración Kennedy, la amenaza comunista ocupaba un lugar central en el diseño de la política italiana de Washington. Un documento del NSC sostuvo por entonces que, si en algún momento los comunistas parecieran a punto de tomar el control del gobierno italiano o de parte del mismo, los Estados Unidos deberían estar dispuestos a actuar, solos o en cooperación con otros aliados, para apoyar a cualesquiera elementos italianos que trataran de evitar el dominio comunista o derrocarlo. El documento excluía una acción militar directa de fuerzas americanas, a no ser que se produjera en concertación con otros aliados europeos, pero no hay nada en el documento que permita excluir la hipótesis de que el NSC contemplara el apoyo a la resistencia armada contra un eventual gobierno comunista, incluso si este se hubiera formado por cauces legales. ${ }^{15}$

\footnotetext{
${ }^{14}$ Col. Luigi Olivieri, Relazione riguardante la Organizzazione O, 22/11/1956, Archivio Storico del Senato della Repubblica (ASSR), CS, Peteano, X, 25.5:

${ }^{15}$ National Seecurity Council, USA: NSC 6014/1, U.S. policy toward Italy, 3/1/1961.
} 
Por otra parte, hay que destacar que no existe prueba alguna de que no sea una falsificación el apéndice $b$ a un manual de campaña del Ejército de Estados Unidos (FM 30-31 B) supuestamente aprobado en 1970, que justificaría acciones desestabilizadoras incluso en países amigos. Según publicaron en 1978 varios medios el apéndice se refería a la amenaza insurreccional a la que estaban expuestos los países en vías de desarrollo amigos de Estados Unidos y afrontaba el caso de que gobiernos de esos países mostraran pasividad o indecisión frente a la subversión comunista, lo que podía ocurrir con facilidad si los comunistas abandonaban temporalmente la violencia. En ese caso recomendaba que los servicios de inteligencia estadounidenses ejecutaran operaciones especiales para convencer al Gobierno y a la opinión pública del país amigo de la realidad del peligro, para lo cual sus agentes debían infiltrarse entre los elementos más radicales e instigarles a la realización de acciones violentas o no violentas. ${ }^{16}$ Ese documento se ha presentado muchas veces como la plantilla del terrorismo que afectó a Italia en los años de plomo, pero no resulta creíble. Una nota del Departamento de Estado sostuvo en 2006 que se trataba de un documento falsificado por los soviéticos en los años setenta, ya que el auténtico manual FM 30-31 sólo tenía un suplemento A. Inicialmente tuvo poca difusión, pero en septiembre 1978 reapareció en dos publicaciones españolas, Triunfo y El País, según el Departamento de Estado por obra de un comunista español y un agente de inteligencia cubano. ${ }^{17}$

La primera referencia a la futura Gladio se halla en una nota que el general Umberto Broccoli, director del SIFAR, envió en octubre de 1951 al jefe del Estado Mayor, para sugerir que Italia participara en la creación de una organización, propuesta por Gran Bretaña, Francia y Estados Unidos, cuya misión sería actuar en territorio ocupado por el enemigo en caso de conflicto entre la OTAN y el bloque comunista, con fines de información, sabotaje, propaganda y resistencia. ${ }^{18}$ En de abril de 1952 el servicio de inteligencia británico envió al SIFAR una invitación a incorporarse al comité de planificación de la organización, pero la propuesta fue descartada por la cúpula militar, debido a que Italia no era tratada en un plano de paridad con los tres fundadores. Se optó en cambio por una relación bilateral con Estados Unidos y en 1953 se comenzó a construir una base de entrenamiento en Capo Marargiu, en la isla de Cerdeña, con financiación de la CIA. El 1 de octubre de 1956 se creó en el seno del SIFAR la sección SAD (Estudios y Adiestramiento) que tendría a su cargo el mando de Gladio. ${ }^{19}$

Finalmente, el 28 noviembre de 1956 se firmó el acuerdo bilateral entre el SIFAR y la CIA que puso en marcha la operación. Se estableció que ambos servicios colaborarían en la organización, adiestramiento y actividad operativa de una red clandestina destinada a actuar en caso de ocupación de territorio italiano tras las líneas enemigas, en tareas de información, sabotaje, evasión y fuga, guerrilla y propaganda. ${ }^{20} \mathrm{El}$ acuerdo no fue comunicado al gobierno en pleno, ni mucho menos al parlamento, pero fue aprobado por el entonces ministro de Defensa Paolo Emilio Taviani, el presidente de la República Giovanni Gronchi, el presidente del Gobierno Antonio Segni, el vicepresidente Giuseppe Saragat y el ministro de Asuntos exteriores Gaetano Martino. ${ }^{21}$ La base de Cerdeña se enmascaró bajo la denominación de Centro de Adiestramiento de Gastadores (CAG) y un año después un grupo de militares destinados en la sección SAD y en el CAG realizaron un curso de preparación en Estados

\footnotetext{
16 Triunfo, 23/9/1978.

${ }^{17}$ US State: Misinformation about 'Gladio/Stay Behind' networks resurfaces, 26-1-2006.

${ }^{18}$ SIFAR, Operazione informativo-operativa nel territorio nazionale suscettibile di occupazione nemica, 8/10/1951, en Flamigni, Sergio (ed.) (2012): Dossier Gladio, Milán, Kaos, pp. 155-162.

${ }^{19}$ Comissione parlamentare di inchiesta sul terrorismo in Italia e sulle cause della mancata individuazone dei responsabili delle stragi: Relazione sull'inchiesta condotta sulle vicende connesse all'operazione Gladio, $15 / 4 / 1992$

${ }^{20}$ Accordo SIFAR-CIA 28/11/1956, ASSR, CS, Gladio, X, 1.6.

${ }^{21}$ Relazione Copasis, p. 104
} 
Unidos. La formación teórica incluyó un análisis de la amenaza comunista, con particular referencia a sus modalidades de infiltración para la conquista "democrática" del poder (que en Italia resultaba más verosímil que una insurrección). Respecto al entrenamiento práctico, los militares italianos concluyeron que las operaciones Stay-Behind, como las de evasión y fuga, en particular de aviadores derribados, recepción aérea y marítima de personas o material y ocultamiento de depósitos, no diferían sustancialmente de las convencionales. ${ }^{22}$

La gestión de Gladio fue encomendada a un comité integrado por ocho miembros del servicio secreto italiano y tres de la CIA, que se reunió con regularidad hasta 1964, año en que Italia se incorporó al Comité Clandestino Aliado y por tanto Gladio dejó de ser una operación bilateral. Tras ello hubo sólo reuniones esporádicas, que en 1973 cesaron por completo. ${ }^{23} \mathrm{Al}$ frente de la operación Gladio estuvieron: el teniente coronel Aurelio Rossi de 1956 a 1966, el coronel Giovanni Romeo de 1966 a 1970, el teniente coronel Pietro Savoca Corona de 1970 a 1971, el teniente coronel Gerardo Serravalle de 1971 a 1974, el coronel Paolo Inzerilli de 1980 a 1986, el teniente coronel Luciano Piacentini de 1987 a 1989 y por último, de 1989 a 1990, el capitán de navío Gianantonio Invernizzi. ${ }^{24}$

Inicialmente Gladio estuvo dotado de muy poco personal nuevo, al margen de los militares que fueron destinados a la sección SAD que dirigía la operación desde Roma y al centro de adiestramiento de Cerdeña, pero en cambio hubo un importante trasvase de miembros de la organización O. Según explicó el SIFAR a la CIA, los veteranos de Ossopo seguían dispuestos, si las circunstancias lo exigían, a luchar por su país y por la libertad contra cualquier forma de comunismo y cuando el Estado Mayor del Ejército disolvió la organización O pasaron a depender del propio SIFAR. En octubre de 1957 se integraron en una unidad denominada Stella Alpina, que contaba con más de mil hombres y abundante armamento y material, y tenía encomendadas misiones de control y neutralización de la actividad eslavo-comunista en tiempo de paz; de lucha antiguerrillera en caso de insurrección interna; y de lucha guerrillera en caso de invasión del territorio nacional. Stella Alpina formaba parte de la organización Stay-Behind, con la diferencia es que en las demás zonas esta se limitaba a constituir el núcleo destinado activar la guerrilla en caso de emergencia, mientras que Stella Alpina se hallaba en un estadio más avanzado de preparación de fuerzas guerrilleras, una singularidad debida, según el SIFAR, a las especiales circunstancias de la región fronteriza en que actuaba. ${ }^{25}$ Como puede verse, las misiones de Stella Alpina, decididas por el SIFAR y comunicadas luego a la CIA, excedían con mucho a las fijadas para la red italiana de Stay-Behind en el acuerdo de 1956, pues no se limitaban a una actuación tras las líneas enemigas en caso de invasión, sino que estaban también dirigidas a combatir la subversión comunista interna. Ello implica que en Gladio se dio desde el principio una flagrante dualidad entre las misiones definidas por el acuerdo fundacional y las que tenía encomendadas en la región fronteriza del Nordeste.

Un documento de junio de 1959, titulado "las fuerzas especiales del SIFAR y la operación Gladio", apunta en la misma dirección, pues preveía su actuación en caso de emergencia "por obra de subversiones internas o de fuerzas militares invasoras". Gladio, en su sentido estricto, contaba por entonces con seis núcleos informativos, diez núcleos de sabotaje, seis núcleos de propaganda, seis núcleos de evasión y fuga y doce de guerrilla, pero además de ello existían cinco unidades guerrilleras de pronto empleo: Stella Alpina en el Friuli, con unos seiscientos hombres preparados, que se programaba llegaran a mil, más otros mil que se podrían movilizar en caso de emergencia; Stella Marina en la zona de Trieste, que estaba previsto

\footnotetext{
${ }^{22}$ Corso negli USA dal gruppo SAD-CAG ott-nov 1957, ASSR, CS, Gladio, X, 6.1.

${ }^{23}$ Comissione Stragi, Relazione Gladio.

${ }^{24}$ Crocoli, Mirko (2017): Nome in codice Gladio, Lainate, Acar, p. 83.

${ }^{25}$ Risposta ai quesiti del Servizio Americano riguardanti il Programma Comune S/B, 26/3/1958, Archivio Flamigni (AF), 89.
} 
alcanzara los doscientos hombres; y Rododendro en el Trentino, Azalea en la provincia de Verona y Ginestra en los lagos lombardos, cada una de las cuales debería alcanzar los cien o doscientos hombres. En conjunto el proyecto suponía llegar a 172 hombres en los núcleos StayBehind y a unos 1500 en las unidades de pronto empleo. ${ }^{26}$ Es decir que la casi totalidad de los efectivos se concentraban en las regiones fronterizas más amenazadas de invasión. Por otra parte todo indica que la lista oficial de 622 efectivos que el servicio secreto militar proporcionó a Andreotti en 1990 y que acabó por hacerse pública, excluía a los miembros de las unidades de pronto empleo, pues según esa lista hasta 1959 sólo se habían reclutado 60 hombres. ${ }^{27}$ Cuando en 1965 el general Giovanni De Lorenzo visitó el CAG de Capo Marargiu, se le dijo que la sección SAD contaba con 103 miembros, de los que 72 estaban destinados en el CAG, y las fuerzas especiales contaban con 1500 hombres. ${ }^{28}$ En conclusión: el cómputo de 622 miembros de Gladio no incluía a las "fuerzas especiales del SIFAR", cuyo componente esencial era Stella Alpina.

Italia no permaneció mucho tiempo al margen de la red europea Stay-Behind. En 1959, el SIFAR entró en el Comité de Planificación y Coordinación (CPC) del Cuartel General de la OTAN en Europa y en 1964, el servicio de inteligencia militar italiano, que había pasado a denominarse Servicio de Información de la Defensa (SID) se incorporó al Comité Clandestino Aliado (ACC), integrado por Estados Unidos, Gran Bretaña, Francia, la República Federal Alemana, los Países Bajos, Bélgica y Luxemburgo. En 1968 el SID recibió una nueva directiva de la OTAN para la guerra no ortodoxa, que implicaba el uso de recursos militares no tradicionales y clandestinos en territorios ocupados, para identificar y perturbar operaciones, instalaciones o unidades enemigas, contribuir al debilitamiento moral del enemigo, dar apoyo directo a las operaciones tácticas ortodoxas, apoyar y coordinar a los elementos locales de resistencia y cooperar en la evasión y fuga de personas. ${ }^{29} \mathrm{El}$ concepto de guerra no ortodoxa de la OTAN no implicaba pues otra cosa que no fueran las acciones tras las líneas enemigas.

Según explicaría años más tarde el general Inzerilli, que había estado al mando de la operación Gladio, el CPC, del que no formaba parte Portugal, que era miembro de la OTAN, pero no era un Estado democrático, servía de enlace entre el Cuartel general de la OTAN en Europa y los servicios secretos de los distintos países. Inicialmente lo presidía el Grupo Permanente integrado por Estados Unidos, Gran Bretaña y Francia, pero cuando esta última abandonó la organización militar de la OTAN, fue sustituida por Alemania. Su misión era trazar las líneas maestras de la guerra no ortodoxa, es decir la acción de las fuerzas especiales y los servicios secretos en territorios ocupados por el enemigo, pero la aceptación e implementación de sus directivas dependía de cada servicio de inteligencia nacional. Gladio era por tanto una fuerza nacional, que no dependía del mando militar de la OTAN, pero que coordinaba sus actividades con los servicios de inteligencia aliados a través del CPC, que a su vez estaba conectado con el cuartel general de la OTAN. Una semana al año el CPC se reunía para la realización de un juego de guerra y para el debate de problemas concretos, pero la utilidad de las reuniones era según Inzerilli limitada, por la reticencia de los distintos servicios a mostrar del todo la fuerza de sus efectivos y su despliegue. El Comité Clandestino Aliado era un órgano más técnico, en el que no participaban ni Portugal ni Grecia ni Turquía, y en el que se intercambiaba información útil. Aunque inicialmente Italia estaba atrasada respecto a los demás aliados, fue desarrollando importantes competencias, sobre todo en los campos de la guerra psicológica y de la guerrilla. Los ejercicios conjuntos solían realizarse cada tres años,

\footnotetext{
${ }^{26}$ Le forzi speciali del SIFAR e l'operazione Gladio, 1/6/1959, en Flamigni, pp. 264-271.

${ }^{27}$ Relazione Copasis, pp. 78-80.

${ }^{28}$ Visita al Centro Addestramento Guastatori del Comandante Generale dell' Arma dei Carabinieri (21-22 giugno 1965), CLD S00843: SIFAR,

${ }^{29}$ Direttiva di SACEUR per la guerra non ortodossa, ASSR, CS, Gladio, X, 5.7: SHAPE V-82-68.
} 
inicialmente siempre en la base británica, que era la principal, en parte porque hasta los años setenta la convicción de Londres era que una invasión soviética no habría sido frenada hasta el canal de la Mancha. Más tarde Italia dirigió los ejercicios conjuntos en 1980, Francia en 1983, e Italia de nuevo en $1986 .^{30}$

El armamento para Gladio fue enviado por la CIA y a partir de 1961 se enterró en depósitos clandestinos, conocidos como Nasco. Un documento de noviembre de 1990 hace constar que la mayoría fueron enterrados en 1962 y 1963 y los dos últimos lo fueron en 1971. El material de los Nasco incluía 144 ametralladoras Sten, 180 carabinas Winchester, 210 pistolas Star, 32 pistolas de calibre 22 con silenciador, 619 kilos de explosivo C4, 29 artefactos incendiarios y 843 bombas de mano. Si suponemos que cada hombre debería contar con al menos un arma de fuego el arsenal bastaría para 583, una cifra que encaja bien con la lista oficial de los 622 que habría reclutado Gladio a lo largo de su historia. Ello implica que Stella Alpina y las demás fuerzas especiales contarían con armamento propio, procedente al menos en parte de la organización O. ${ }^{31}$ De hecho la comisión parlamentaria de investigación sobre el terrorismo pudo averiguar que en 1957 había depósitos clandestinos de armamento en 48 cuarteles de los Carabineros y 15 del Ejército, que Gladio había heredado de la organización O. ${ }^{32}$

\section{El desmantelamiento parcial de Gladio a partir de 1972}

El 24 de febrero de 1972 los Carabineros examinaron un depósito de armamento que unos adolescentes habían hallado por azar en la localidad de Aurisina, cercana a Trieste. En realidad, era un Nasco y aunque el coronel Serravalle, que estaba al frente de Gladio, estimó que no había peligro de que se descubriera su origen, porque no eran armas que las Fuerzas Armadas italianas tuvieran en dotación, envió al capitán Zazzaro a inspeccionarlo. Este comprobó que se trataba del Nasco 203, pero que faltaban algunos elementos y que los contenedores con las armas no se habían hallado en el lugar donde se habían depositado, sino a 400 metros, en una hondonada y tapados por ramas, por los que supuso que algunos buscadores de residuos bélicos, numerosos en la zona, los habrían encontrado y escondido con intención de llevárselos más adelante. ${ }^{33} \mathrm{El}$ 4 de marzo se descubrió otro contenedor en los alrededores y los Carabineros hicieron explotar el explosivo que contenía, por considerarlo inestable. Serravalle, en su comparecencia ante la comisión parlamentaria de investigación sobre el terrorismo, afirmó muchos años después que ello no tenía explicación, porque el C4 que contenían los Nasco era muy estable, y también mostró su extrañeza ante el hecho de que los Carabineros no hubieran dejado inspeccionar al capitán Zazzaro el material hallado, sino que se limitaron a consignarle una lista y unas fotografías en blanco y negro ${ }^{34}$.

La confrontación entre el material encontrado en el Nasco de Aurisina y el depositado originalmente reveló la desaparición de parte de este, incluidos 4,8 kilos de explosivo C4 y dos detonadores mecánicos, pero en cambio se encontraron otros explosivos que no procedían del depósito original. Tras ello, el entonces teniente coronel Serravalle, también preocupado por la actitud de algunos miembros de Gladio, propuso a la dirección del SID el desmantelamiento completo de los Nasco, que comenzó en abril de $1972 .{ }^{35}$ El ya general Serravalle explicó años más tarde en su comparecencia ante la comisión parlamentaria que, tras ser nombrado responsable de Gladio en octubre de 1972, había efectuado entrevistas por separado con unos

\footnotetext{
${ }^{30}$ Inzerilli, Paolo (2007): La vittoria dei gladiatori: da Malga Porzus all'assoluzione di Rebibbia, Bietti Media.pp. 60-64.

${ }^{31}$ Relazione Copasis, pp. 87-91.

${ }^{32}$ Comissione Stragi, Audizione di Gerardo Serravalle, 19/11/1990, pp. 638-640.

${ }^{33}$ Relazione Copasis, pp. 91-97.

${ }^{34}$ Comissione Stragi, Serravalle, 19/11/1990, pp. 599-600 y 636

${ }^{35}$ Sentenza del Tribunale di Roma, 3/7/2001, en Flamigni, pp. 435-445.
} 
quince jefes locales, los más carismáticos, casi en su totalidad del Friuli y muchos de ellos antiguos partisanos de Ossopo. Comprobó entonces que casi la mitad de ellos eran partidarios de una acción preventiva contra los comunistas locales, que sin duda habrían apoyado una invasión soviética. Serravalle decidió entonces que tenía que prescindir de ellos, si no quería convertirse en el jefe de una banda armada. Sus preocupaciones se extendían al coronel Aldo Specogna, que estaba al mando del Centro Ariete, del que dependían las unidades guerrilleras del Noreste: Stella Alpina y Stella Marina, pero sólo explicó que este coronel resultaba peligroso porque hablaba demasiado. Algo grave se debía sin embargo sospechar porque el almirante Mario Casardi, jefe del SID entre 1974 y 1977, llegó a decir que, si el servicio de inteligencia militar italiano hubiera sido de otro tipo, Specogna hubiera muerto en un accidente de tráfico. ${ }^{36}$

De hecho, Speogna murió en su cama en 1982, pero a raíz de los hechos narrados perdió el mando del Centro Ariete. En septiembre de 1973 fue nombrado adjunto suyo Giuseppe Cismondi, que pronto lo sustituyó y permaneció en el cargo hasta 1978. Cismondi retiró el armamento para las unidades de pronto empleo que se hallaba depositado en los cuarteles de los Carabineros y prescindió de unos 600 hombres que habían servido a las órdenes de Specogna, pero acerca de este tema se mostró muy reacio a dar detalles en su comparecencia ante la comisión parlamentaria, aunque admitió haber ordenado la destrucción de los listados en que figuraban sus nombres. Admitió también que la decisión de retirar la totalidad del armamento a disposición de los efectivos de Gladio en la región bajo su mando había sido tomada a raíz que el 6 de mayo de 1976, con ocasión del terremoto del Friuli, aparecieran armas y explosivos en el sótano de un sacerdote, quien informó de ello a un oficial de los Alpinos que a su vez telefoneó a Specogna, aunque quien le cogió el teléfono fue el propio Cismondi. Este creía que el depósito provenía de tiempos de la Resistencia y que el sacerdote y el oficial eran personas ligadas a la Ossopo. ${ }^{37}$ Ello sugiere que la red de contactos de Specogna, que procedía de treinta años atrás, se mantenía viva al margen de lo que era la estructura oficial de Gladio,

Retirado el armamento de los Nasco y de los depósitos clandestinos situados en los cuarteles y reducidos sus efectivos en el Noreste, Gladio había quedado sustancialmente redimensionada, lo que condujo a que los Estados Unidos pusieran en cuestión el acuerdo bilateral de 1956. La CIA no había sido consultada previamente acerca del desmantelamiento los Nasco, que contenían material de guerra proporcionado por Estados Unidos, y decidió suspender su ayuda financiera a Gladio. Sin embargo, en octubre de 1972, su jefe en Italia Howard Stone insinuó que la operación podría seguir siendo válida si se la rediseñaba para hacer también frente a subversiones internas. Un informe de Serravalle del 4 de diciembre hizo sin embargo notar que esa misión interna no formaba parte del acuerdo de 1956 y aunque se había planteado en el ámbito del SIFAR en 1959, no se había traducido en preparativos efectivos. ${ }^{38}$ Así es que el memorándum de entendimiento que la CIA y el SID firmaron el 20 de diciembre de 1972 no previó una función interna, la financiación estadounidense se redujo a la exigua suma de 3.000 dólares anuales, el suministro de material americano cesó y los Estados Unidos renunciaron al uso de la base en Cerdeña, aunque se ofrecieron a seguir compartiendo sus experiencias en materia de guerra no ortodoxa. ${ }^{39}$

Este memorándum de entendimiento, de vigencia trianual, caducó en 1975 y nunca fue renovado, con lo que la financiación estadounidense cesó por completo. ${ }^{40}$ Gladio mantuvo su conexión con la red Stay-Behind, pero quedó muy debilitado. Un informe de diciembre de

\footnotetext{
${ }^{36}$ Comissione Stragi, Serravalle 19/11/1990, pp.: 630-634, y 22/11/1990, pp. 9-17.

${ }^{37}$ Comissione Stragi, Audizione di Giuseppe Cismondi, 10/1/1991.

${ }^{38}$ Relazione Copasis, pp. 47-48

${ }^{39}$ Serravalle, Gerardo (1991): Gladio, Roma, Edizioni associate, pp. 94-98.

${ }^{40}$ Relazione Copasis, pp. 105-111.
} 
1975 del coronel Paolo Inzerilli, su nuevo jefe, se refería a la falta de efectivos, la insuficiente actividad de adiestramiento y la precariedad de armamento y material, hasta el punto de que Gladio no estaría en condiciones de activarse en caso de emergencia. Entre 1974 y 1976 fueron suprimidas Stella Alpina y las demás unidades de pronta intervención. ${ }^{41}$

Según explicaría el general Inzerilli en 2017, la red Stay-Behind se había fundado cuando la Europa continental no contaba con ejércitos capaces de hacer frente a una invasión soviética y por tanto su tarea primordial era la acción guerrillera tras las líneas enemigas. Pero en los años setenta todos los países, incluida Italia, contaban con ejércitos fuertes y la acción guerrillera perdió importancia en la planificación frente a las de información y de evasión y fuga. En la práctica, sin embargo, la red Gladio sólo se activó en misión informativa cuando el general estadounidense Dozier fue secuestrado en 1981 por las Brigadas Rojas. ${ }^{42}$

\section{El lado oscuro de Gladio}

El gran interrogante en la historia de Gladio es por qué se tomó a partir de 1972 la drástica decisión de retirar los depósitos de armas y prescindir de buena parte de los hombres procedentes de la brigada partisana Ossopo que integraban la principal unidad guerrillera. No se sabe cómo se tomó la decisión, pero resulta inverosímil suponer que no tuviera el consentimiento del entonces presidente del Gobierno, Giulio Andreotti. En cuanto a sus motivos, la pista fundamental es la que dio el general Serravalle: algunos jefes de la organización en el Friuli, antiguos partisanos, mostraban una inquietante proclividad a actuar preventivamente contra los comunistas locales.

El acuerdo el SIFAR con la CIA no preveía que la operación Gladio tuviera una misión interna de combatir el comunismo, pero el citado documento del SIFAR de 1959 sí mencionaba su actuación en caso de "subversiones internas", una expresión que puede entenderse referida a una insurrección que pusiera en peligro la autoridad del gobierno legítimo, tal como lo interpretó la comisión parlamentaria de control de los servicios de inteligencia. ${ }^{43}$ Pero esa misma comisión averiguó también que en octubre de 1958 el SIFAR explicó a la CIA que las misiones de Stella Alpina incluían en tiempos de paz el control y la neutralización de la actividad comunista. ${ }^{44}$ No cabe pues dudar de que al menos Stella Alpina tenía encomendada una misión distinta de la actuación tras las líneas enemigas en caso de invasión, que era la razón de ser de las operaciones Stay-Behind. Sus miembros podían pensar que controlar a la futura quinta columna era también una forma de prepararse para la eventualidad de una invasión, pero ¿a qué se refería el SIFAR con la neutralización de la actividad comunista? Por otra parte no se ha hallado ningún indicio de que tales propósitos se tradujeran en acciones efectivas. ${ }^{45}$

La misión anticomunista interna de Gladio fue un tema prioritario para los fiscales militares de Padua Sergio Dini y Benedetto Roberti, que investigaron inicialmente a Gladio y cuyos interrogatorios de antiguos miembros de la organización arrojan mucha luz sobre la misma. A Francesco B., que durante el servicio militar había hecho un curso de radiotelegrafista, se le propuso a fines de los sesenta incorporarse a una organización que habría de preparar la resistencia, en caso de una invasión soviética o de una insurrección que pretendiera establecer una dictadura. Cuando aceptó se le dijo que era una organización dependiente de los servicios secretos italianos pero encuadrada en la OTAN y su adestramiento

\footnotetext{
${ }^{41}$ Comissione Stragi, Relazione Gladio, p. 24.

${ }^{42}$ Commissione parlamentare di inchiesta sul rapimento e sulla morte di Aldo Moro (Comissione Moro):

Audizioni di Paolo Inzerilli, 8/3/2017 y 23/5/2017.

${ }^{43}$ Relazione Copasis, p. 106.

${ }^{44}$ Relazione Copasis, pp. 38-39.

${ }^{45}$ Relazione Copasis, p. 108.
} 
se limitó a algún curso de radio en su propia ciudad. Luciano $S$, que había hecho el servicio militar como paracaidista, fue contactado en 1957 y participó en una decena de adiestramientos, casi siempre en un lugar de cuya localización no se le informó, pero luego supo que estaba en Cerdeña. Se le explicó que la función principal de la organización era promover la resistencia en caso de ocupación soviética y nada se le dijo respecto a los comunistas italianos, pero él estaba personalmente convencido de que en caso de conflicto habría que actuar también contra ellos. Giuseppe L., también del Friuli, fue contactado en los primeros años setenta, hizo tres cursos de adiestramiento en un lugar que luego supo que estaba situado en Cerdeña y participó en muchos ejercicios de evasión en Friuli. En la base sarda se les dijo que debían vigilar a los comunistas de su localidad, porque si hubiera una invasión la apoyarían y sería necesario detenerlos y deportarlos. Se les dijo también que, si los comunistas llegaban al poder, incluso por vía electoral, los miembros de Gladio no tendrían más opción que huir al extranjero u organizar la resistencia, incluso militar, contra el régimen comunista. A Marco Z., de Trento, le contactaron a mediados de los sesenta, para participar en una organización que entraría en acción en caso de invasión extranjera y no se le dijo nada acerca de su eventual utilización contra una subversión interna, pero en conversaciones informales con otros miembros oyó comentar que la organización entraría en acción si una facción extremista se hacía con el poder mediante la violencia, pero que no se actuaría en caso de una victoria electoral de las izquierdas. En una base que luego supo que estaba en Cerdeña se adiestró en el uso de armas de la OTAN y del Pacto de Varsovia y en sabotajes mediante explosivos. A Duilio M., que se incorporó a comienzos de los sesenta y sirvió como radiotelegrafista, se le dijo que la organización debía oponerse a la toma del poder por los comunistas, sin que nunca se precisara si debían actuar también en el caso de que la toma del poder fuera por vía electoral. Giuseppe Ianuzzi que fue comandante de la base sarda desde septiembre de 1972 a septiembre de 1973, declaró que el adiestramiento iba encaminado a operaciones de guerra no ortodoxa y que esta consistía esencialmente la neutralización de eventuales quintas columnas filosoviéticas en el territorio nacional. ${ }^{46}$

Gladio realizó un solo ejercicio en el que se practicaran operaciones de insurgencia y contrainsurgencia, el ejercicio Delfino, que se efectuó del 15 al 24 de abril de 1966 en la Venecia Julia y de cuya realización el SIFAR informó previamente a la CIA, como era habitual. ${ }^{47}$ Según un informe del 6 de mayo, el ejercicio consistió esencialmente en la organización de un sistema de conexiones clandestinas por radio a larga distancia, una operación nocturna de evasión por vía marítima y la organización y activación de mandos para operaciones de insurgencia y contrainsurgencia. Participaron 22 elementos locales (es decir voluntarios) y 9 de la sección SAD (es decir militares en activo). El escenario hipotético comprendía un lapso de tiempo de diez meses, a lo largo de las cuales se sucederían una primera fase de agitación subversiva, una segunda de insurrección abierta y un tercera en la que las autoridades habrían optado por ceder el control temporal de la zona a los insurgentes, contra los que se activarían las unidades guerrilleras previamente constituidas. Un grupo se ocupó de programar las acciones de insurgencia y otro las de contrainsurgencia, que incluirían propaganda, interrupción de mítines y manifestaciones, acciones intimidatorias, movilización de asociaciones patrióticas, sobre todo estudiantiles, y fichaje de los elementos favorables a la insurrección. En la tercera fase de la insurrección se podría llegar a la realización de actos de terrorismo que se atribuirían a los insurrectos. ${ }^{48}$

Es evidente que los supuestos en que se basó el ejercicio Delfino no respondían tanto a la realidad de 1964 como a la de los primeros años de la República, en los que una insurrección

\footnotetext{
${ }^{46}$ Procura militare di Padova, 1991, CLD, CS, Gladio, X, 5.

${ }^{47}$ SIFAR, Esercitazione Delfino, CLD, CS, S791-792.

${ }^{48}$ Relazione Copasis, pp. 43-46.
} 
comunista con apoyo yugoslavo no era una hipótesis descabellada. Pero lo grave era que implicaban una gran desconfianza respecto al Gobierno italiano, del que se presuponía que podría claudicar frente a la amenaza eslavo-comunista, y una disposición a recurrir a la lucha armada al margen de la voluntad gubernamental. En aquellos momentos había un gobierno de centro-izquierda, con participación socialista, presidido por el democristiano Aldo Moro. En cuanto a la previsión de que se realizaran actos terroristas para culpar de ellos a los insurrectos, no es necesario destacar su gravedad, ya que encaja en el concepto de una estrategia de la tensión que también podría haberse aplicado en tiempos de paz y que algunos creen que de hecho estaba detrás de los atentados neofascistas que se sucedieron entre 1969 y 1974. Según el comité parlamentario de control de los servicios secretos, fue el único ejercicio en el que se plantearon operaciones de contrainsurgencia, pues en todos los demás el supuesto era la actuación tras las líneas enemigas. ${ }^{49}$

Quienes en 1991 quisieron ver en Gladio la matriz de una estrategia de la tensión encaminada a crear un clima de temor en la población para evitar el avance comunista, acusaron a la organización de estar implicada en gravísimos atentados, que habían sido cometidos, pero no reivindicados, por elementos neofascistas. Por ello se esforzaron en buscar conexiones fascistas de Gladio, pero tuvieron poco éxito. De hecho, el componente más inquietante de Gladio en el Noreste, lejos de estar compuesto por ex-fascistas, lo integraban en parte antiguos partisanos antifascistas que veían en el comunismo una nueva amenaza totalitaria. El general Serravalle, que había dirigido Gladio desde 1971 hasta 1974, explicó ante la comisión parlamentaria de investigación sobre el terrorismo que no se reclutaban miembros de ideologías extremas, es decir que se excluía tanto a los comunistas e incluso a los socialistas como a los neofascistas. ${ }^{50}$ De hecho en la lista de los 622 miembros de Gladio que se dio a conocer no aparecía nadie que hubiera estado implicado en violencias neofascistas. El periodista Gianni Barbacetto, que la estudió en detalle, encontró en ella a cuatro ex miembros del Partido Nacional Fascista, a ocho personas que habían apoyado a la República Social Italiana (el régimen colaboracionista con los ocupantes nazis), a un miembro de la X MAS (una unidad militar de élite que combatió a los partisanos) y a nueve miembros del neofascista Movimiento Social Italiano, es decir que sólo un 3,5\% tenían conexiones fascistas pasadas o presentes. ${ }^{51}$ Por otra parte sólo 19 procedían con seguridad de Ossopo, lo cual es otro indicio clarísimo de que los miembros de Stella Alpina no figuraban en esa lista. ${ }^{52}$

En la documentación de Gladio aparecieron también 1.300 casos "negativos", es decir personas que habían sido tomadas en consideración para ser enroladas, pero que habían sido descartadas por distintos motivos. Entre ellos aparecían nombres sospechosos como el de Gianfranco Bertoli, un sedicente anarquista que había cometido un atentado en Milán en 1973, y los neofascistas Enzo Maria Dantini, Gianni Nardi y Marco Morin. ${ }^{53}$ En el caso de Bertoli, la persona que aparecía en el expediente negativo no era el terrorista, pero la polémica continuó porque el juez Casson estaba convencido que, tras haberse él fijado en el nombre de Bertoli durante su primera visita al archivo del SISMI, le había sido luego entregado un expediente manipulado para hacer creer que se trataba de otro. ${ }^{54} \mathrm{El}$ propio Bertoli, que siguió

\footnotetext{
${ }^{49}$ Relazione Copasis, p. 108.

${ }^{50}$ Comissione Stragi, Serravalle, 19/11/1990, p. 623.

${ }^{51}$ Barbacetto, Gianni (2009): Il grande vecchio, Milán, Rizzoli, p. 306

${ }^{52}$ Pacini, op. cit. pp. 190-191.

${ }^{53}$ De Lutiis, Giuseppe (1998): I servizi segreti in Italia: dal fascismo alla seconda repubblica, Roma, Editori Riuniti, pp. 326-328.

${ }^{54}$ Comissione Stragi, Audizione del dottor Felice Casson, 14/6/1995.
} 
reivindicando durante sus años de prisión su fe anarquista, desmintió en diciembre de 1990 su pertenencia a Gladio en una carta enviada desde la cárcel a un senador. ${ }^{55}$

En definitiva, no ha aparecido indicio alguno de participación de miembros de Gladio en un atentado, aunque también se ha discutido si en el que costó la vida a tres carabineros en Peteano en 1972 se utilizaron explosivo o detonadores procedentes del Nasco de Aurisina. Esa era la sospecha del juez Casson, pero fue rebatida por otro juez, Guido Salvini, que investigó intensamente el terrorismo neofascista. ${ }^{56}$ El historiador Giacomo Pacini tampoco cree que existiera conexión alguna entre Gladio y los neofascistas que cometieron el atentado de Peteano, pero en cambio le parece indudable que material de Aurisina fue utilizado, sin conocimiento de la dirección de Gladio, por personas desconocidas. ${ }^{57}$

Otro aspecto debatido ha sido la implicación de Gladio, o más bien de Specogna y sus hombres, en el proyecto conocido como Plan Solo, diseñado en 1964 por el general Giovanni De Lorenzo, de acuerdo con el presidente de la República Antonio Segni, que preveía la intervención exclusiva de los Carabineros, al margen de las previsiones legales, para poner fin a una eventual movilización callejera comunista. ${ }^{58}$ En diciembre de 1990 el general Luigi Tagliamonte declaró ante el juez Mastelloni que el propio De Lorenzo le había explicado que el plan preveía la deportación de los detenidos a la base del cabo Marrargiu. Y en 1994 Lino Micoli, que había sido responsable de la custodia del armamento del Centro Ariete, declaró que en el verano de 1964, el general De Lorenzo trasmitió una contraseña a Specogna para que pusiera en alerta a sus hombres con la misión de aniquilar a los comunistas de la región, aunque luego envió una contraorden. ${ }^{59}$ Los portavoces de la asociación de antiguos miembros de Gladio desmintieron en rueda de prensa las afirmaciones de este testigo, sosteniendo que a sus ochenta años confundía fechas y nombres, y que había pertenecido a la organización O, pero no había formado parte de Gladio ${ }^{60}$

El general Serravalle, en un libro publicado meses después de su comparecencia ante la comisión parlamentaria, negó también que hubiera habido conexión entre Gladio y el Plan Solo y argumentó que la base de Cerdeña no disponía de instalaciones para albergar a los 730 detenidos que estaba previsto deportar. Estaba convencido de que ninguno de los dirigentes de Gladio estuvo implicado en intentos golpistas ni colaboró en atentados. Le parecía sin embargo inquietante que la existencia de Gladio fuera conocida por personas ajenas a la organización e implicadas en tramas golpistas o terroristas. Su opinión era que a fines de los años sesenta y comienzos de los setenta había existido realmente una estrategia de la tensión, que había sido fruto de una conexión entre elementos desviados de los servicios secretos y terroristas de extrema derecha, hasta que los primeros perdieron el control y la estrategia quedó en manos de asesinos y paranoicos. ${ }^{61}$

\section{Investigaciones parlamentarias y judiciales sobre Gladio}

Gladio salió a la luz en la investigación del juez Felice Casson acerca del atentado de Peteano de 1972, en el que murieron tres Carabineros y en cuya investigación el coronel del cuerpo Dino Mingarelli siguió deliberadamente una pista falsa, lo que retrasó en años la identificación

\footnotetext{
55 ASSR, CS, Gladio, X, 19.

${ }^{56}$ Sentenza-ordinanza del Giudice Istruttore dr. Guido Salvini, Tribunale Civile e Penale di Milano, 3/2/1998, cap. 31.

${ }^{57}$ Pacini, op.cit. pp. 238-246.

${ }^{58}$ Franzinelli, Mimmo (2010): Il Piano Solo: I servizi segreti, il centro-sinistra e il 'golpe' del 1964. Milán, Mondadori.

${ }^{59}$ Sentenza-ordinanza del dottor Carlo Mastelloni, Tribunale Civile e Penale di Venezia, 10/12/1998, pp. 13621363 y $1376-1378$

${ }^{60}$ ANSA, 26/8/1994.

${ }^{61}$ Serravalle, op.cit. Gladio, pp. 34-56.
} 
de sus verdaderos autores neofascistas. ${ }^{62}$ Según reveló más tarde la prensa, en diciembre de 1989 el general Pasquale Notarnicola, hasta 1983 miembro del SISMI, reveló a Casson que el almirante Fulvio Martini, quien en 1990 era jefe de dicho servicio, le había dicho que tras el atentado de Peteano se había desplazado a la zona para evitar que la justicia pudiera descubrir algunos depósitos de armas pertenecientes al SISMI. El 15 de enero de 1990 Martini admitió la existencia de los depósitos y cuatro días después Casson escribió a Andreotti para que le permitiera acceder a la documentación del SISMI. Finalmente, el 20 de julio el juez fue recibido por el jefe del presidente, que le autorizó el acceso a los archivos del servicio en Forte Braschi, en los que apareció la documentación de Gladio ${ }^{63}$.

No se sabe qué motivos impulsaron a Andreotti a permitir que un juez investigara en los archivos del servicio secreto militar ni a revelar luego la existencia de una estructura militar clandestina vinculada a la OTAN. La explicación más sencilla es que, un año después de la caída del muro de Berlín, Gladio resultaba escasamente relevante y era una pieza que se podía sacrificar, demostrando así una voluntad de transparencia y de colaboración con la justicia, sin peligro real porque Andreotti debía saber bien que aquella organización secreta no estaba implicada en conductas delictivas. Pero se ha sugerido también, por el general Inzerilli, entre otros, que Andreotti utilizó a Gladio para evitar que la atención se orientara hacia otro esqueleto más inquietante que se escondía en el armario de la República, el de los misteriosos Núcleos para la Defensa del Estado.

Lo cierto es que el 27 de noviembre de 1990 el gobierno italiano decretó la disolución de Gladio y ese mismo día Andreotti decidió revelar a la comisión parlamentaria de investigación sobre el terrorismo la identidad de todos los voluntarios que habían formado parte de la organización, una decisión que no tomó ningún otro de los Estados miembros de la OTAN en los que existían estructuras semejantes. La lista de miembros no tardó en filtrarse a la prensa, que la dio a conocer por entero, creando problemas familiares, sociales y profesionales a algunos de ellos. Los miembros de Gladio se sintieron traicionados por el Estado y sobre todo por Andreotti. ${ }^{64}$

La documentación de Gladio fue intervenida por diversas autoridades judiciales, incluida la Fiscalía de Roma, la Fiscalía Militar de Padua y los jueces instructores Casson y Mastelloni. El SISMI invocó el secreto de Estado respecto a algunos documentos, como el acuerdo entre la CIA y el SIFAR de 1956 y las actas de los comités de Stay-Behind. Andreotti no confirmó el secreto de Estado respecto al acuerdo de 1956, pero mantuvo prohibida su divulgación, al igual que respecto a las actas del Comité de Coordinación Aliado, mientras que afirmó la inviolabilidad de las del Comité de Planificación y Coordinación, que no pudieron ser consultadas por la justicia. ${ }^{65}$

En noviembre de 1991 el presidente de la República Francesco Cossiga se denunció a sí mismo ante la Fiscalía de Roma, alegando que su responsabilidad respecto a la red Gladio, cuya plena legitimidad afirmaba, le hacía partícipe del supuesto delito de conspiración política por el que el juez Casson había imputado, en el auto del 10 de octubre en que transfirió el caso a la Fiscalía de Roma, al almirante Fulvio Martini y al general Inzerilli, director y jefe del Estado Mayor del SISMI. Un mes después los fiscales militares de Padua Sergio Dini y Benedetto Roberti imputaron a otros militares que habían formado parte de Gladio, entre ellos el general Gerardo Serravalle, que había sido su jefe en los años críticos de 1971 a 1974.

\footnotetext{
${ }^{62}$ Pacini, op.cit. 231-246.

${ }^{63}$ Panorama, 29/10/1990.

${ }^{64}$ Tosolini, Franco (2003): Da Porzûs a Gladio, tesi di laurea, Milán, Università Cattolica del Sacro Cuore, pp. 95-96.

${ }^{65}$ Comissione Stragi, Relazione Gladio.
} 
Un informe realizado por el abogado general del Estado, Giorgio Azzariti, sostuvo que Gladio no podía considerarse una sociedad secreta prohibida por la Constitución, ya que el precepto constitucional no se refería a estructuras creadas por el Estado, que como norma general debían someterse al escrutinio público, pero no cuando concurría el secreto militar. Un caso distinto habría sido la participación de Gladio en un golpe de Estado, como el preparado por el llamado Plan Solo de 1964, en el que estaba previsto el internamiento de los miembros de la oposición detenidos en la base de Gladio en Cerdeña. Sin embargo, el hecho de que los conspiradores que prepararon el plan previeran la utilización con fines subversivos de instituciones como Gladio o el Cuerpo de Carabineros no implicaba la ilegitimidad de estas. Por último, el abogado general sostenía que el acuerdo entre el SIFAR y la CIA de 1956, que había dado origen a Gladio, no requería de autorización parlamentaria, ya que no se trataba de un tratado internacional sino de una aplicación del tratado de la OTAN, que amparaba los acuerdos bilaterales entre los Estados miembros. ${ }^{66}$

Tras revelarse la existencia de Gladio, se comenzó a hablar también de otra organización secreta, que se dio en llamar Gladio Roja. Ya en marzo de 1990 un semanario había exigido al Partido Comunista Italiano, que por entonces se disponía a cambiar de nombre y de programa, que abriera sus archivos y aclarara ciertos aspectos de su historia, sobre todo en los años decisivos de 1945 a 1950 en que Italia se jugó mantener la libertad o caer en el estalinismo como la Europa del Este. ¿Tenía por entonces una organización paramilitar clandestina dispuesta para lanzar una insurrección cuando el balance de fuerzas le fuera favorable ${ }^{67} \mathrm{Un}$ año después, en junio de 1991, el senador democristiano Paolo Emilio Taviani, miembro destacado de la Resistencia, ministro de Defensa en los años cincuenta y varias veces ministro del Interior en los años sesenta y setenta, explicó que los comunistas habían contado con un numeroso aparato clandestino, dotado de armas cortas y con acceso a depósitos de armas largas, que estaba en contacto con los servicios secretos checoslovacos en unos tiempos en que la amenaza de una invasión de Italia era real, pero que gradualmente se había debilitado hasta ser desmantelado por Enrico Berlinguer, quien llegó la secretaria general del PCI en 1972. ${ }^{68}$ Documentos incriminatorios de los servicios de inteligencia acerca de este aparato clandestino fueron enviados a la Fiscalía de Roma en junio 1991. Esta sin embargo archivó el caso en marzo de 1994, con el argumento de que no era posible demostrar que ni el apoyo recibido de la URSS por el PCI ni la creación de un aparato defensivo por parte de este hubiera traspasado los límites de lo lícito, aunque reconoció lo inquietante que resultaban las referencias a la asistencia de comunistas italianos a cursos de sabotaje, de armas y explosivos y de comunicaciones radiofónicas clandestinas impartidos en países del Este. ${ }^{69}$

El Comité parlamentario para los servicios de información y seguridad, presidido por el democristiano Tarcisio Gitti, concluyó en su informe de 1992 que la operación Gladio había respondido al derecho y el deber de adoptar las medidas necesarias para la defensa de Italia en el contexto de la Guerra Fría. Respecto a su supuesta implicación en actos gravísimos que estaban siendo investigados por los jueces, sostuvo que no había ni pruebas ni indicios concretos, aunque ello no consintiera llegar a conclusiones definitivas. El informe minoritario presentado por el vicepresidente Aldo Tortorella, del poscomunista Partido Democrático de Izquierda, sostuvo en cambio que Gladio había sido una organización armada clandestina, al margen de la Constitución, que veía como enemigo a una parte del pueblo italiano. ${ }^{70}$

\footnotetext{
${ }^{66}$ Studio prodotto dall'avvocato generale dello Stato, en Flamigni, op.cit. pp. 121-132.

${ }^{67}$ L'Europeo, 11-17/3/1990

${ }^{68}$ Comissione Stragi, Audizione di Paolo Emilio Taviani, 19/6/1991.

${ }^{69}$ ASSR, CS, Gladio Rossa, XI-XIII, 1.2.

${ }^{70}$ Relazione Copasis.
} 
El informe final de la comisión parlamentaria de investigación sobre Gladio, presentado en abril de 1992 por su presidente, el senador republicano Libero Gualtieri, concluyó en cambio que Gladio había sido ilegal desde su origen, ya que el SIFAR no estaba capacitado para firmar acuerdos internacionales y tampoco podía ampararse en la legitimidad de la OTAN, porque no formaba parte de ella. Destacaba además la poca información que sobre la operación habían tenido los vértices del Estado. Pero lo más grave del informe era la afirmación de que Gladio había participado en una estrategia que, creando elementos de tensión, había justificado la necesidad de intervenciones estabilizadoras. Una afirmación que insinuaba su implicación en acciones violentas, aparentemente desestabilizadoras, aunque en realidad tendentes a reforzar la adhesión al status quo de una población atemorizada. Faltaban sin embargo en el informe de Gualtieri las referencias concretas a en qué podría haber consistido la implicación de Gladio en esa estrategia de la tensión. ${ }^{71}$

La comisión parlamentaria de investigación sobre el terrorismo nunca llegó a consensuar un informe final sobre el conjunto de los temas que investigó, pero su segundo presidente, el senador del Partido Democrático de Izquierda Giovanni Pellegrino, presentó en diciembre de 1995 un esbozo en el que dedicó un capítulo a Gladio. Su tesis era que representaba una pieza de la historia oculta de Italia, pero que era un error buscar en ella la clave interpretativa de la estrategia de la tensión y de las matanzas terroristas no esclarecidas. No había pruebas de que hubiera estado implicado en actividades ajenas a su misión, salvo en tareas informativas, ni con propósitos contrarios a determinadas fuerzas políticas, aunque la documentación sobre el tema era incompleta. El plan Solo había previsto la utilización de Gladio, pero la organización como tal no estuvo implicada. En definitiva, Gladio no podía considerarse una organización penalmente ilícita, pero no cabía excluir que hubiese sido utilizada con fines ilícitos. ${ }^{72}$

Los miembros de la comisión pertenecientes al Partido Democrático de Izquierda, un partido socialdemócrata surgido en 1991 de la transformación del Partido Comunista Italiano, presentaron en 2000 un informe minoritario mucho más duro. Sostuvieron que, para impedir que las fuerzas de izquierda italianas llegaran democráticamente al poder, se había reclutado a elementos de derechas para que constituyeran estructuras clandestinas en la órbita de las Fuerzas Armadas, tales como Gladio y otras formaciones paramilitares, incluidos los Núcleos de Defensa del Estado, que eran de carácter subversivo y terrorista y estaban ligadas a exponentes de los servicios secretos y las Fuerza Armadas italianas, a la logia masónica P2, a la CIA y a la OTAN. Pero una vez más, esas gravísimas acusaciones no se apoyaban en pruebas. $^{73}$

En definitiva, las investigaciones parlamentarias no encontraron pruebas concretas de que Gladio hubiera estado implicado de alguna manera en la supuesta estrategia de la tensión. Las investigaciones judiciales, que se prolongaron durante una década, tampoco las encontraron, a pesar del volumen de documentación que se consultó. El 22 de diciembre de 1990 la Fiscalía de Roma se incautó de 136.508 documentos relativos a Gladio en los archivos del SISMI, a los que se sumaron unos 13.000 entregados más tarde. Sin embargo, según la sentencia que dictó el tribunal de primera instancia de Roma en 2001, muchos documentos habían sido destruidos anteriormente, no siempre de acuerdo con los procedimientos debidos. La serie G, de documentación interna de Gladio se había conservado íntegra, pero no así las

\footnotetext{
${ }^{71}$ Comissione Stragi, Relazione Gladio.

${ }^{72}$ Comissione Stragi: Proposta di relazione presentata dal presidente della Comissione, senatore Giovanni Pellegrino, 12/12/1995.

${ }^{73}$ Comissione Stragi: Relazione del Gruppo Democratici di Sinistra - L'Ulivo, Stragi e terrorismo in Italia dal dopoguerra al 1974, 22/6/2000.
} 
series H y B que contenían la correspondencia con la CIA. ${ }^{74}$ Según el informe pericial que el profesor Giuseppe de Lutiis presentó en 1994 al juez Grassi del tribunal de Bolonia, muchos documentos fueron destruidos en 1990, inmediatamente después del primer acceso del juez Casson a los archivos, y la documentación incautada se halló en un completo desorden sólo atribuible a una intervención dolosa, porque era impensable que un archivo gestionado por servicios secretos militares pudiera carecer de cualquier tipo de orden lógico o cronológico. ${ }^{75}$

En particular, la documentación referente los comités aliados que coordinaban las redes Stay-Behind no pudo ser examinada por la justicia italiana. En diciembre de 1993 el Cuartel General de la OTAN en Europa requirió al SISMI que destruyera los documentos secretos y le entregara los calificados de máximo secreto, que habían sido secuestrados por la Fiscalía de Roma y luego devueltos al SISMI tras confirmar el Presidente del Gobierno su inviolabilidad. No es sin embargo probable que fuera en esa documentación donde pudieran encontrarse pruebas de que Gladio se hubiera apartado de las misiones atribuidas a las redes Stay-Behind, pues habría implicado que el servicio secreto italiano hubiera informado de ello a todos los servicios aliados. ${ }^{76}$

El juez Casson, cuya investigación había llevado a que Gladio saliera a la luz, tuvo que renunciar al caso por motivos de jurisdicción territorial, ya que era a un tribunal de Roma al que correspondía investigar los presuntos delitos de una organización cuya sede central estaba en Roma. Así es que en octubre de 1991 hubo de renunciar a la instrucción que había iniciado respecto al almirante Martini y el general Inzerilli. Lo hizo mediante un auto en el que sostuvo la ilegitimidad de Gladio por haber surgido de un acuerdo secreto entre la CIA y el SIFAR, que carecía de competencia para firmar tratados internacionales, sin que se hubiera informado al Parlamento. Según Casson, su finalidad no había sido sólo la actuación contra una ocupación extranjera, sino que se preveía su intervención en caso de conflicto interno, habiendo realizado funciones de espionaje político, social, cultural, económico e industrial. Había utilizado a elementos de la derecha subversiva, entre los que citaba a Marco Morin y Enzo Maria Dantini (que la documentación del SISMI incluía entre los "negativos"), a Gianfranco Bertoli y Mario Portolan (aunque el SISMI sostuviera que tales extremistas no eran las personas que aparecían en la documentación sino meros homónimos) y a los desconocidos que habían utilizado el Nasco de Aurisina como depósito de armamento. Casson sostenía incluso que el atentado de Peteano no era sino uno de los varios en los que habían participado personas pertenecientes a, o al menos relacionadas con, Gladio. $^{77}$

A pesar de su dureza, este auto no aportaba en realidad pruebas de que nadie vinculado a Gladio hubiera participado en atentados. Por ello, algún antiguo miembro de la organización vio el lado positivo de que un magistrado como Casson, del que no cabía sospechar benevolencia respecto a Gladio, lo hubiera investigado. ${ }^{78}$

Por su parte, los fiscales militares de Padua Sergio Dini y Benedetto Roberti habían imputado en diciembre de 1991 a los antiguos responsables de Gladio Gerardo Serravalle, Fausto Fortunato, Giuseppe Cismondi, Bernardo de Bernardi, Pietro Savoca y Giovanni Romeo por haber promovido y organizado, en estrecha conexión con la CIA, una banda armada que actuaba en el Veneto y en Friuli-Venecia Julia con el propósito de obstaculizar la formación de una mayoría parlamentaria de izquierda y preparar una acción violenta para el caso de que se formara. Ambos fiscales sostuvieron que Gladio estaba con toda probabilidad estructurada en

\footnotetext{
${ }^{74}$ Sentenza del Tribunale di Roma, en Flamigni, pp. 483-485.

${ }^{75}$ Perizia del professore Giuseppe de Lutiis consegnata il $1^{\circ}$ luglio 1994 al giudice isttruttore Leonardo Grassi el tribunale di Bologna, ASSR, CS, Gladio, XI-XIII, 4.6:

${ }^{76}$ Direttiva Renzi, PCM, 2113, 38: CESIS 18/12/1993, Archivio Centrale dello Stato (ACS).

77 AF, Sentenza di incompetanza del Giudice Istruttore di Venezia dottor Felice Casson, 10/10/1991.

${ }^{78}$ Tosolini, op.cit. pp. 109-110.
} 
varios niveles con diferentes líneas de mando y con diversidad de funciones. El nivel integrado por personal no comprometido en actividades extremistas, como era el caso de los 622 incluidos en la lista que el gobierno había hecho pública, tenía como función la resistencia en caso de invasión y se incardinaba en las estructuras de la OTAN. Pero había una estructura más profunda, que constituía el verdadero núcleo de los intereses estadounidenses en Italia, estaba formada por individuos hasta el momento desconocidos y tenía como misión impedir el crecimiento electoral del PCI y su acceso al poder y preparar la reacción en caso de que se produjera. ${ }^{79}$ No es necesario subrayar el carácter altamente especulativo de estas afirmaciones de los fiscales Dini y Roberti. En todo caso, su investigación concluyo en febrero de 1992, fecha en que se les ordenó el traslado del caso a la Fiscalía Militar de Roma, que a su vez lo traspasaría a la Fiscalía ordinaria.

En los tribunales de Roma la primera causa que se sentenció fue la generada por la autoacusación del presidente de la República. En julio de 1994 la sala para los delitos cometidos por ministros absolvió a Cossiga, por no existir indicios de que Gladio como tal fuera una organización delictiva y porque, aún en el caso de que la organización o parte de la misma pudiera haber sido utilizada de forma desviada para fines diferentes de los establecidos, él no había tenido relación alguna con actividades que fueran penalmente relevantes. ${ }^{80}$

Dos años después, en 1996, la fiscalía de Roma llegó a sus propias conclusiones acerca del caso que habían abierto por separado el juez Casson y los fiscales militares de Padua. Sostuvo que las posibles actividades encaminadas a la lucha política interna que pudieran haber tenido lugar antes de 1972 sólo podían tener un interés histórico, pero que se podía excluir que Gladio hubiera sido utilizada para fines penalmente relevantes tras el desmantelamiento del "sector más expuesto" en los primeros meses de aquel año. No había prueba de que se hubieran cometido anteriormente delitos achacables a la organización y no a miembros individuales, que en todo caso habrían prescrito, y nada podía imputarse a quienes rigieron la organización desde 1972 y en particular al general Serravalle, que había sido el artífice de la interrupción de actividades peligrosas. Por tanto, la Fiscalía solicitó que se archivara la causa por el delito de haber constituido una organización armada con el fin de impedir por medios violentos un cambio político. Por el contrario solicitó que fueran enviados a juicio el almirante Martini y el general Inzerilli, por haber dificultado la investigación mediante la destrucción de documentos y la desorganización del archivo, y por haber sostenido falsamente que Gladio no había tenido más fines que los relativos a la defensa en caso de invasión extranjera, ocultando las razones verdaderas de la reestructuración de la red en 1972; así como el capitán Invernizzi por haber ordenado la destrucción de los cuadernos redactados por los voluntarios de Gladio durante su entrenamiento en la base de Cerdeña. ${ }^{81}$

Es decir que finalmente los máximos responsables de Gladio en los últimos años, el almirante Fulvio Martini, director del SISMI desde 1984 hasta 1991, y el general Paolo Inzerilli, responsable de la operación Gladio desde 1974 hasta 1986 y jefe de Estado Mayor del Sismi desde 1986 hasta 1990, sólo fueron juzgados por haber dificultado la investigación. La hipótesis del fiscal era que los acusados habían ocultado información para impedir que se esclareciera el atentado de Peteano, debido a que al producirse este habían surgido en el ámbito de Gladio sospechas de que en el mismo hubiera podido emplearse explosivo procedente del Nasco de Aurisina; pero el tribunal no estimó que hubiera prueba alguna de ello y absolvió en julio de 2001 a Martini, Inzerilli e Invernizzi. Con ello puso fin al itinerario judicial del caso Gladio. ${ }^{82}$

\footnotetext{
${ }^{79}$ Procura militare di Padova: "L'operazione Gladio", CLD, CS, Gladio, X, 5.

${ }^{80}$ Collegio per I reati ministeriali presso il tribunale di Roma, 8/7/1994, ASSR, CS, Gladio, XI-XIII, 4.25.

${ }^{81}$ Procura della Repubblica di Roma, 15/7/1996, ASSR, CS, Gladio, XI-XIII, 4.23.

${ }^{82}$ Sentenza del Tribunale di Roma, en Flamigni 2012, op. cit. pp. 423-428, 503-513 y 530-531.
} 


\section{Conclusiones}

La acusación formulada en 1990 por sectores de izquierda italiana de que Gladio gestionó una estrategia de la tensión que recurría a atentados terroristas tuvo un cierto eco internacional. Fue recogida incluso en uno de los estudios de conjunto sobe el siglo XX que más influencia han tenido, el del historiador marxista británico Eric Hobsbawm, quien sostuvo que Gladio, en Italia y quizá en otros países, se nutrió inicialmente de fascistas y en los años setenta, cuando ya no era verosímil una invasión soviética, se reorientó hacia el terrorismo de derechas, que a veces actuó con un disfraz de izquierdas. ${ }^{83}$ La documentación disponible permite concluir que nada ello tiene fundamento. Gladio fue sencillamente la componente italiana de la red StayBehid, creada en varios estados democráticos europeos para actuar tras las líneas enemigas en caso de invasión soviética y no hay una sola prueba que la implique en atentados terroristas.

Sin embargo, subsisten algunas cuestiones no resueltas. La primera se refiere a los motivos reales de su desmantelamiento parcial a partir de 1972. ¿Respondió simplemente al deseo de prescindir de unos hombres cuyas ideas encajaban mal con los principios democráticos y ya no eran necesarios? ¿Fue una medida preventiva ante el temor de que los hombres del coronel Specogna pasaran a la acción? ¿Había indicios de que parte de ellos estuvieran implicados en tramas golpistas o en contacto con el terrorismo neofascista del Noreste? En tanto no haya salido a la luz la documentación relevante, será difícil responder a estas preguntas, pero parece probable que quienes decidieron el desmantelamiento parcial de Gladio en los años setenta tuvieran serias razones para ello.

La segunda cuestión se refiere a los motivos que tuvo Andreotti para revelar en 1990 la existencia de la organización. En una reciente entrevista el general Inzerilli se ha referido a Andreotti como un político de altísimo nivel, cínico en grado sumo y carente de piedad incluso hacia los amigos si ello le servía para sus propósitos, que habría revelado la existencia de Gladio en parte para obtener el apoyo comunista en su intento de llegar a la presidencia de la República y en parte por proteger a los Núcleos de Defensa del Estado, de cuya existencia algo debía saber y sobre cuya actividad estaba investigando la justicia. ${ }^{84} \mathrm{Y}$ ante la nueva comisión parlamentaria de investigación sobre el caso Moro, Inzerilli se ha mostrado aún más explícito. Ha declarado que, metafóricamente, habían existido tres Gladio, el blanco es decir aquel al que él mismo había pertenecido, el rojo, es decir la organización secreta del Partido Comunista, y el negro, es decir los Núcleos de Defensa del Estado, que habrían sido disueltos entre 1972 y 1973. Según el general, tales núcleos dependían directamente del ministro de Defensa, cargo que Andreotti desempeñó desde 1959 hasta 1966 y de nuevo en 1974, e incluían a extremistas de derecha, como el coronel Amos Spiazzi, procesado por su presunta participación en la intentona golpista del príncipe Borghese, pero finalmente absuelto, y Vincenzo Vinciguerra, autor confeso del atentado de Peteano. En 1990 los Núcleos de Defensa del Estado estaban siendo investigados por el juez Salvini y, en opinión del general, Andreotti tenía motivos para desviar la atención pública hacia la inocua operación Gladio. ${ }^{85}$.

Es difícil evaluar si estas declaraciones de Inzerilli tienen fundamento o si se trata de una venganza contra el ya fallecido Andreotti. Lo cierto es que no se sabe cuáles fueron los motivos que le impulsaron a autorizar el desmantelamiento parcial de Gladio en 1972 ni cuáles le llevaron a revelar la existencia de Gladio en 1990. Tampoco se sabe apenas nada de los presuntos Núcleos de Defensa del Estado, acerca de los cuales no se dispone de documentación. En cambio, puede afirmarse que en los años sesenta y setenta, los de las tramas golpistas y los

\footnotetext{
${ }^{83}$ Hobsbawm, Eric (1994): Age of extremes; the short Twentieth Century, 1914-1991, London, Michael Josep. p. 165.

${ }^{84}$ Crocoli, op.cit. pp. 281-286.

${ }^{85}$ Comissione Moro: Audizioni di Paolo Inzerilli, 8/3/2017 y 23/5/2017.
} 
atentados terroristas, la democracia italiana corrió un peligro que sus gobiernos lograron evitar. El desmantelamiento parcial de Gladio pudo formar parte de las acciones preventivas tomadas a inicios de los setenta para desactivar la amenaza, pero lo que resulta indudable, a la luz de la documentación analizada en este artículo, es que Gladio no fue la estructura oculta que movió los hilos de la supuesta estrategia de la tensión.

\section{Fuentes y Bibliografía}

a) Archivos

Archivio Centrale dello Stato (ACS), Roma.

Archivio Flamigni (AF), Oriolo Romano.

Archivio Storico del Senato della Repubblica (ASSR), Roma..

Centro di Documentazione Cultura della Legalità Democratica (CLD), Florencia.

\section{b) Documentos}

Comissione parlamentare di inchiesta sul terrorismo in Italia e sulle cause della mancata individuazone dei responsabili delle stragi (Comissione Stragi): Audizioni.

Comissione Stragi: Relazione sull'inchiesta condotta sulle vicende connesse all'operazione Gladio, 15/4/1992.

Comissione Stragi: Proposta di relazione presentata dal presidente della Comissione, senatore Giovanni Pellegrino, 12/12/1995.

Comissione Stragi: Relazione del Gruppo Democratici di Sinistra - L'Ulivo, Stragi e terrorismo in Italia dal dopoguerra al 1974, 22/6/2000.

Commissione parlamentare di inchiesta sul rapimento e sulla morte di Aldo Moro (Comissione Moro): Audizioni.

Comitato Parlamentare per i Servizi d'Informazione e Sicurezza e per il segreto di Stato (Copasis): Relazione, 4-3-1992.

Sentenza-ordinanza del dottor Carlo Mastelloni, Tribunale Civile e Penale di Venezia, 10/12/1998.

Sentenza-ordinanza del Giudice Istruttore dr. Guido Salvini, Tribunale Civile e Penale di Milano, 3/2/1998.

c) Estudios

Aga-Rossi, Elena (2012): “L'eccidio di Porzûs e la sua memoria”, en Piffer, T. ed.: Porzûs: Violenza e Resistenza sul confine orientale, Bolonia, Il Mulino.

Barbacetto, Gianni (2009): Il grande vecchio, Milán, Rizzoli.

Crocoli, Mirko (2017): Nome in codice Gladio, Lainate, Acar.

De Lutiis, Giuseppe (1998): I servizi segreti in Italia: dal fascismo alla seconda repubblica, Roma, Editori Riuniti.

Flamigni, Sergio, ed. (2012): Dossier Gladio, Milán, Kaos.

Franzinelli, Mimmo (2010): Il Piano Solo: i servizi segreti, il centro-sinistra e il 'golpe' del 1964. Milán, Mondadori.

Inzerilli, Paolo (2007): La vittoria dei gladiatori: da Malga Porzus all'assoluzione di Rebibbia, Bietti Media. 
Nuti, Leopoldo y Riste, Olav, (eds.): "Preparing for a Soviet Occupation: the Strategy of StayBehind", Journal of Strategic Studies, vol.30, nº 6 (2007).

Oliva, Gianni (2002): Foibe: le stragi negate degli italiani della Venezia Giulia e dell'Istria, Milán, Mondadori.

Pacini, Giacomo (2014): Le altre Gladio: la lotta segreta anticomunista in Italia, 1943-1991, Turín, Einaudi.

Scotti, Giacomo (2005): Dossier foibe. San Cesareo di Lecce, Manni,

Serravalle, Gerardo (1991): Gladio, Roma, Edizioni associate.

Tosolini, Franco (2003): Da Porzûs a Gladio, tesi di laurea, Milán, Università Cattolica del Sacro Cuore. 